TITLE:

\title{
Experimental high resolution forecasting of volcanic ash hazard at Sakurajima, Japan
}

\section{$\operatorname{AUTHOR(S):~}$}

Poulidis, Alexandros Panagiotis; Takemi, Tetsuya; Iguchi, Masato

\section{CITATION:}

Poulidis, Alexandros Panagiotis ... [et al]. Experimental high resolution forecasting of volcanic ash hazard at Sakurajima, Japan. Journal of Disaster Research 2019, 14(5): 786797

ISSUE DATE:

2019-08-01

URL:

http://hdl.handle.net/2433/244114

\section{RIGHT:}

Publisher permitted to deposit the accepted manuscript on this repository. 発行元の許可 を得て登録しています.; この論文は出版社版でありません。引用の際には出版社版をご 確認ご利用ください。; This is not the published version. Please cite only the published version. 


\title{
Experimental High-Resolution Forecasting of Volcanic Ash Hazard at Sakurajima, Japan
}

\author{
Alexandros Panagiotis Poulidis ${ }^{\dagger}$, Tetsuya Takemi, Masato Iguchi \\ Disaster Prevention Research Institute, Kyoto University \\ Gokasho, Uji, Kyoto 611-0011, Japan \\ †Corresponding author, E-mail: poulidis.alexandros.6z@kyoto-u.ac.jp \\ [Received 00/00/00; accepted 00/00/00]
}

\begin{abstract}
A high-resolution forecast methodology for the ash hazard at Sakurajima volcano, Japan, is presented. The methodology employs a combined modeling approach and utilizes eruption source parameters estimated by geophysical observations from Sakurajima, allowing for a proactive approach in forecasting. The Weather Research and Forecasting (WRF) model is used to downscale Japan Meteorological Agency (JMA) forecast data over the area of interest. The high-resolution meteorological data are then used in FALL3D model to provide a forecast for the ash dispersal and deposition. The methodology is applied for an eruption that occurred on June 16, 2018. Disdrometer observations of ashfall are used along with ash dispersal modeling to inform the choice of the total grain size distribution (TGSD). A series of pseudo-forecast ash dispersal simulations are then carried out using the proposed methodology and estimated TGSD, initialized with meteorological forecast data released up to $\sim 13$ hours before the eruption, with results showing surprising consistency up to $\sim 10$ hours before the eruption. Using forecast data up to 4 hours before the eruption was seen to constrain observation to model ratios within a factor of 2-4 depending on the timing of simulation and location. A number of key future improvements for the methodology are also highlighted.
\end{abstract}

Keywords: volcanic ash, tephra, dispersal modeling, ash hazard forecast, FALL3D

\section{Introduction}

Volcanic eruptions can introduce hazardous amounts of volcanic ash into the atmosphere, adversely affecting the surrounding areas. Airborne ash constitutes a hazard both for international aviation $[1,2]$ as well as the local communities, affecting air quality [3] and health [4,5]. In cities near active volcanoes, deposited volcanic ash also constitutes a hazard to vulnerable infrastructure [6,7], imposing a constant economic burden [8]. Real-time forecasting is vital both in order to monitor airborne ash concentration but also in order to inform short- and long-term response by local governments and decision makers.
In recent years, owing to significant advances in seismology, satellite observations, ground deformation measurement techniques, as well as a deeper understanding of the underlying processes of magma fragmentation and tephra transport and deposition, the accuracy of volcanic activity forecasting has increased drastically $[9,10]$. However, at their current stage ash concentration forecasts are usually constrained within a factor of 10 due to uncertainties in the eruption source parameters (ESPs), such as the mass discharge rate $(\dot{M})$ and the grain size distribution (GSD) of the ejected material $[11,12]$. Furthermore, due to difficulties in connecting the internal signals tied to magma movement (e.g. seismicity and ground deformation) and the eruption outcome (e.g. total erupted mass, volcanic plume height), accurate forecasts are usually reactive, hinging on the volcanic plume height, observed either visually or by remote sensing [13].

Sakurajima volcano is a complex stratovolcano located on the island of Kyushu in the south of Japan $(31.58 \mathrm{~N}$, $130.65 \mathrm{E}$, peak height $1117 \mathrm{~m}$; Fig. 1), and is one of Japan's most active and closely monitored volcanoes [1416]. The volcano has a long eruptive history [17], but despite its potential for larger eruptions, since 2008 it has been erupting mainly with ash-rich vulcanian eruptions [18], i.e. moderated-sized short eruptive bursts [19] leading to volcanic plume heights from a few hundred meters up to a few kilometers $[3,20,21]$. The Sakurajima Volcanological Observatory (SVO), Disaster Prevention Research Institute (DPRI) of Kyoto University operates a Particle-Size-Velocity (parsivel) disdrometer network in order to monitor ashfall over the volcano. Parsivel disdrometers are laser-optical disdrometers used to measure the number, size and fall speed of hydrometeors and ash particles $[15,22]$. The OTT Parsivel ${ }^{2}$ disdormeters used have operating limits of $0.2-25 \mathrm{~mm}$ for the particle size and $0.2-20 \mathrm{~m} \mathrm{~s}^{-1}$ for the velocity. In order to monitor magma movement, the observatory also operates a broadband seismometer network (STS-2 Streckeisen seismometers; frequency range: $0.0083-50 \mathrm{~Hz}$ ) and has installed a set of 2-component radial tangential water-tube tilt meters and 3-component radial, tangential and oblique extensometers are installed along $28 \mathrm{~m}$ of an underground tunnel to the southeast of the vent [21].

The volcano's long-lasting activity and impact on the surrounding area $[3,23]$ make accurate localized forecasts 

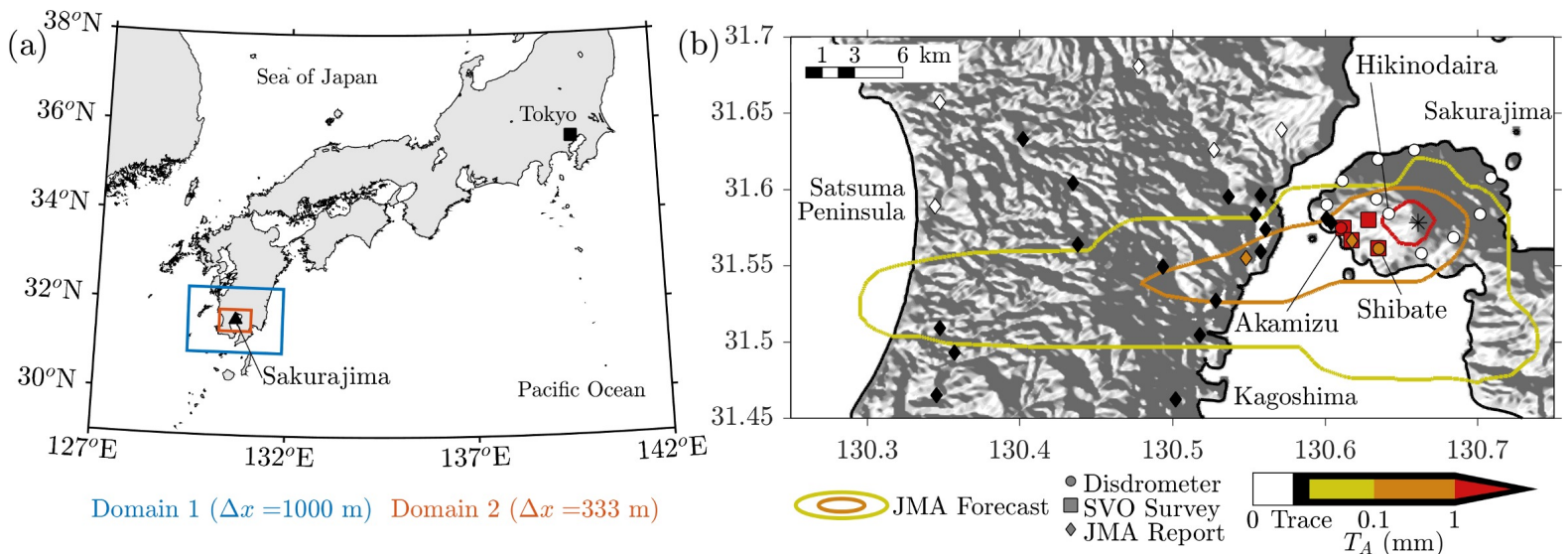

Fig. 1. (a) Location of Sakurajima in Japan and the boundaries of the two WRF model domains and the respective horizontal grid spacing used $(\Delta x)$. (b) Dispersal of volcanic ash from the 16 June 2018 eruptions (vent noted with an asterisk marker). Disdrometer locations are shown with circle markers, Sakurajima Volcanological Observatory (SVO) post-eruption survey sampling locations are shown with square markers and Japan Meteorological Agency (JMA) observations are shown with diamond markers. Marker color indicates observed ash deposit thickness. White markers indicate no ashfall and black markers indicate ashfall confirmation but without associated thickness values. The JMA forecast is shown with colored contours, using the same colors as the deposits to allow for a comparison.

a necessity. The Japan Meteorological Agency (JMA) is responsible for the volcanic hazard management and forecasting for active volcanoes in Japan and operates the Volcanic Ash Fall Forecast (VAFF) system. As a part of the system, JMA uses a Lagrangian transport model to run scheduled forecasts of lapilli and ashfall in three hour blocks using forecast data, as well as emergency forecasts for eruptions with plume heights over $2.5 \mathrm{~km}$ agl [13]. However, even at the finer local forecast resolution used (horizontal grid spacing of $2 \mathrm{~km}$ ), the forecasts are too coarse to fully resolve localized circulations and windplume interactions $[24,25]$, which can in turn affect dispersal and deposition of volcanic ash [3,26, 27].

In this study we present initial results from an experimental forecasting methodology carried out at the SVO. Unlike the JMA which has a nation-wide mission, the SVO can focus specifically on Sakurajima, allowing for better defined ESPs, as well as higher model resolutions. The paper is organized as follows. Initially, the eruption used as a case study is then introduced in Section 2. The proposed forecast methodology used is then detailed in Section 3. Details on the determination of the GSD used in the study are presented in Section 4. Results from an initial "control" simulation are presented in Section 5, while results from pseudo-forecast simulations are presented in Section 6. Finally, Section 7 summarizes the main conclusions of the study and presents a brief discussion on future perspectives.

\section{June 16, 2018 Eruption Details}

The volcano erupted on the morning of June 16, 2018 (0719 Japan Standard Time; JST=UTC+9), with a reported plume height of $4700 \mathrm{~m}$ above ground level (agl)

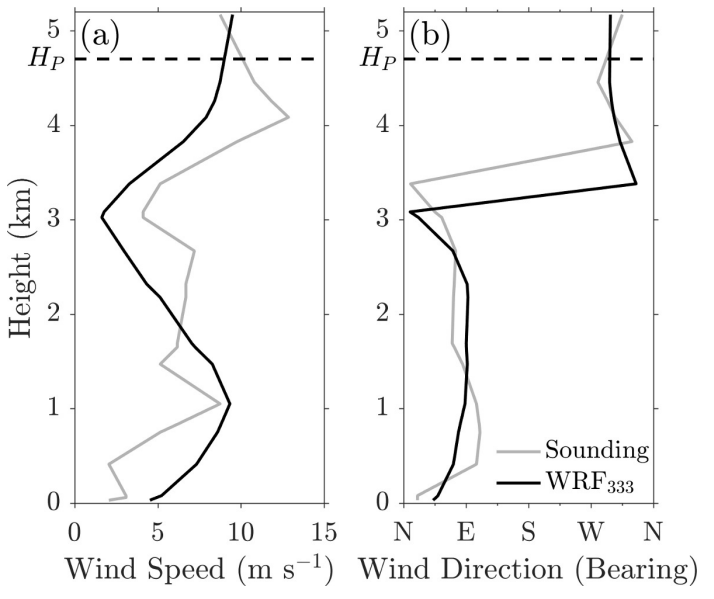

Fig. 2. Vertical profile of: (a) wind speed, and (b) wind direction. Values are shown at 0900JST on June 16, 2018. Atmospheric sounding data from the Kagoshima meteorological station (31.55N/130.55E; World Meteorological Organization (WMO) code:47827) are shown in gray and WRF results from the innermost domain $(\Delta x=333 \mathrm{~m})$ averaged around a $3.5 \mathrm{~km}$ radius from the meteorological station location and are shown in black. The horizontal dashed line indicates the observed plume height $\left(H_{P}=4700 \mathrm{~m}\right)$. Wind direction indicates the bearing (i.e. origin of the wind).

and a pyroclastic flow that flowed for approximately $1300 \mathrm{~m}$ [28]. Ashfall was observed west and southwest of the volcano, as far as the southern end of Satsuma peninsula [28]. Locations of reported ashfall were digitalized from the JMA report and the ones included in the computational domains used are shown in Fig. 1b. This deposition pattern agrees with an atmospheric profile that was observed a few hours after the eruption (0900JST; Fig. 2). The vertical wind profile was marked by substantial wind 
shear (a common feature in the area [29]): wind direction was northwesterly near the top of the plume, and easterly at $3 \mathrm{~km}$ changing over a shallow shear layer $(\sim 3-4 \mathrm{~km})$. The eruption was chosen for this case study as it represents a typical example of a large eruption in the current phase of Sakurajima, had a dedicated report by the JMA, and ashfall was captured well at the disdrometer locations.

A post-eruption survey carried out by the SVO showed that large ashfall deposits $\left(\sim 2 \mathrm{~kg} \mathrm{~m}^{-2}\right.$ or $>1 \mathrm{~mm}$ in thickness) were concentrated over the southwestern shore of Sakurajima (Fig. 1b). Ash deposit thickness was also measured by JMA personnel after the eruption at two points [28], at the western shore of Sakurajima (reported as 'approximately $1 \mathrm{~kg} \mathrm{~m}^{-2}$, or $0.83 \mathrm{~mm}$ ) and over Kagoshima (reported as 'between $0.1-1 \mathrm{~mm}$ '). Finally, ashfall was also observed at two parsivel disdrometer locations near the southwestern shore of the volcano (Fig. 1b): Akamizu (AKA) to the west of the vent (final deposit thickness $1.7 \mathrm{~mm}$ ) and Shibate (SHI) to the southwest of the vent $(0.36 \mathrm{~mm})$. Ashfall was not registered at any other disdrometer location. The difference between the SVO, JMA and disdrometer sampling is possibly the result of the specific location of the sampled area; as the volcano emits ash in an almost continuous matter [26] such differences can be expected. In the case of the disdrometers an added issue is ashfall due to particles of sizes less than the cut-off limit $(0.2 \mathrm{~mm})$; however, the impact is expected to be relatively small due to the proximity to the vent. Note that the conversion between ash load $\left(\mathrm{kg} \mathrm{m}^{-2}\right)$ and deposit thickness $(\mathrm{mm})$ was carried out using a deposit density of $1200 \mathrm{~kg} \mathrm{~m}^{-3}$, a commonly used value (e.g. [30]) which is less that the individual particle density to account for the inclusion of air in the deposit.

The ash hazard forecast released by JMA after the eruption [31] was also digitalized and is shown in Fig. 1b. Overall, the dispersal axis for the ash was forecasted successfully, showing ash deposition south-southwest of the vent, with the observed wind direction shear accounting for the wide fanning of the ash dispersal. The largest deviations in the forecast can be seen over the volcano. Judging from the SVO survey and ash deposits observed by the disdrometer network, ash deposition over Sakurajima occurred over a narrow area, southwest of the vent. The JMA forecast shows ash deposition over almost the entirety of the volcano, excluding the northern shore. Furthermore, the location of maximum deposition (marked with the red contour) is exclusively near the vent and fails to include the ashfall observed at the Akamizu disdrometer location, while including a disdrometer that registered no ashfall just west of the vent at the Hikinodaira peak. This is possibly due to a misrepresentation of the plume shape as well as the relatively coarse resolution of the data used to drive the Lagrangian ash dispersal modeling. The forecast is used as a benchmark to compare the results of the proposed method against.

The SVO uses a novel method [21] for estimating eruptable mass for eruptions using an empirical relation- ship between seismological and deformation data as:

$$
M_{T}=c_{1} A+c_{2} V+c_{3}
$$

where $M_{T}$ is the ejected material weight (in tons), $A$ is the seismograph spectrum sum between $2-3 \mathrm{~Hz}\left(\mathrm{~m} \mathrm{~s}^{-1}\right), V$ is the pressure source volume change sum $\left(\mathrm{m}^{3}\right)$, and $c_{3}$ is a corrective term for reducing noise in seismograph data. The values for the parameters $\left(c_{1}=3.8 \times 10^{-5}, c_{2}=2.6, c_{3}=-\right.$ $1.3 \times 10^{5}$ ) were calculated using monthly ashfall data that had been gathered by the Kagoshima prefectural government in 62 stations from 2009-2013 so that the Pearson product-moment correlation coefficient is maximized. The method was tested both for individual eruptions and the monthly sum of eruptions and was seen to provide an accurate estimate for the total erupted mass with errors at approximately $10 \%$ for individual eruptions and $20-30 \%$ for monthly data (see [21] for details).

These estimates can be used to study temporal changes in the build-up of mass leading up to the eruption (Fig. 3). In the case studied here the estimates show a progressive increase in eruptable mass starting 17 hours before the eruption. The mass accretion was gradual and occurred in three stages between 17-14, 10-9 and 3-2 hours before the eruption, followed by plateaus with relatively small changes. Estimated mass peaked at $4.5 \times 10^{8} \mathrm{~kg}$ just before the eruption, when most of the mass $\left(3.2 \times 10^{8} \mathrm{~kg}\right)$ was ejected within 10 minutes (gray area in Fig. 3). This significant initial decrease is used as the main eruption studied here. The decrease continued for $20 \mathrm{~min}$ after that at a declining rate. This is a typical temporal evolution in the current eruptive phase of the volcano. Ashfall at the two disdrometer locations started $\sim 20 \mathrm{~min}$ after the eruption and lasted for 40-60 min.

\section{Forecast Methodology}

The proposed methodology uses a combined modeling approach. Initially, version 4 of the Weather Research and Forecasting (WRF) model $[32,33]$ is used to dynamical downscale JMA's Meso-Scale Model (MSM) forecast data. MSM data are released every 3 hours ( 0 to 21 UTC) and include 39 hours of forecast data at a $5 \mathrm{~km}$ horizontal grid spacing $(\Delta x)$ [34]. Two one-way-nested domains are used in WRF ( $\Delta x=1000$ and $333.3 \mathrm{~m})$, with a progressive focus over Kyushu and the Kagoshima prefecture (Fig. 1a). Vertical grid spacing increases from 50 to $1000 \mathrm{~m}$, with the model top situated at $\sim 16.5 \mathrm{~km}$. For all simulations the topography was based on the Geospatial Information Authority of Japan (GSI) $50 \mathrm{~m}$ digital elevation model (DEM). The WRF simulations are all carried out over the same period (15/06/2018 2100JST to $16 / 06 / 2018$ 0900JST) in order to provide consistent meteorological data to use for the ash dispersal modeling (carried out between 0719-0849JST). For forecast data released after the initial time of the simulation the final forecast at previous timings was used. Rayleigh damping is imposed over the top $5 \mathrm{~km}$ to reduce the errors from gravity waves reflected at the domain top [35], while sixth- 


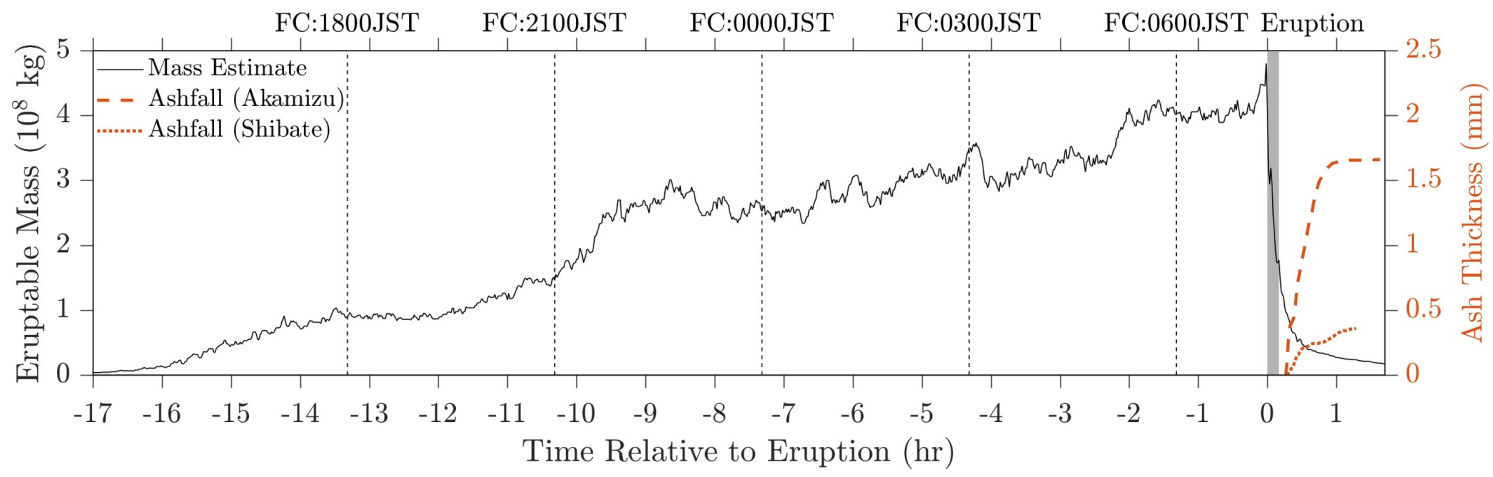

Fig. 3. Estimated eruptable mass (left-hand $y$-axis) shown in black and accumulated ash deposit thickness (right-hand $y$-axis) shown in orange. The different line styles indicate the two disdrometer locations (see legend). The eruption time (16/06/2018; 0719JST) is marked as $0 \mathrm{hr}$, while negative (positive) hours denote the time before (after) the eruption. "FC" notes indicate the release of Meso-Scale Model (MSM) forecast data, while the gray shaded area marks the eruption.

order monotonic horizontal diffusion is applied to minimize spurious behavior at poorly resolved scales [36]. Domain details are summarised in Table 1.

Table 1. WRF and FALL3D model domain description.

\begin{tabular}{cccccc}
\hline Domain & $n_{x}$ & $n_{y}$ & $n_{z}$ & $\Delta x, \Delta y(\mathrm{~m})$ & $\Delta t(\mathrm{~s})$ \\
\hline WRF D1 & 237 & 163 & 58 & 1000 & 5 \\
WRF D2 & 238 & 163 & 58 & 333.3 & 1.67 \\
FALL3D & 163 & 93 & 60 & 300 & 2.9 \\
\hline
\end{tabular}

A full physical parameterization suite is used (Table 2). Note that a planetary boundary layer (PBL) scheme is used for both domains. At a grid spacing of $333.3 \mathrm{~m}$ the innermost domain cannot resolve all turbulent motion [37] as it falls within the "turbulence gray zone" for atmospheric convection where turbulence is neither entirely parameterized nor resolved by a large eddy simulation (LES) scheme [38]. Although not ideal, due to computational constrains simulations at this resolution are common both in a forecast [39] and research setting [27,30].

Table 2. Modeling schemes used if WRF (•) and FALL3D (o).

\begin{tabular}{lc}
\hline Scheme & Option \\
\hline - Boundary Layer & YSU[40] \\
- Microphysics & Morrison[41] \\
- Radiation & RRTMG[42] \\
- Surface Layer & MM5[43-47] \\
- Land Surface & MM5[48] \\
$\circ$ Volcanic Plume & FPLUME[49] \\
○ Particle Aggregation & Costa[50,51] \\
- Terminal Velocity & Ganser[52] \\
- Stream-wise Air Entrainment & Kaminksi-C[53] \\
$\circ$ Cross-wise Air Entrainment & Tate[54] \\
\hline
\end{tabular}

Version 7.2 of FALL3D, a 3D time-dependent Eulerian model that solves the advection-diffusion-sedimentation equation $[55,56]$, is used to simulate the transport and deposition of volcanic ash. The FALL3D domain cov- ers Sakurajima and a part of the Satsuma peninsula to the west of the volcano, including most of the city of Kagoshima (Fig. 1b). Domain details are similar to the WRF innermost domain, although the model top is limited at $6000 \mathrm{~m}$ with a constant grid height of $100 \mathrm{~m}$ in order to reduce computational time (see Table 1 ). The plume morphology is estimated using the coupled FPLUME model $[49,57]$, a 1D steady-state volcanic plume model based on the buoyant plume theory [58]. FALL3D accounts for a number of volcanological effects and atmosphere-plume interactions (e.g. air entrainment $[59,60]$, plume bending and particle fallout inside the plume [25], particle reentrainment [61], water phase changes [62], plume collapse [57]) and offers different schemes for ash particle terminal velocity [52] and ash aggregation - the joining of airborne ash particles [63]. Aggregation works either by scavenging fine particles to create larger ones $[63,64]$ or, as was noticed in a recent study over Sakurajima, by forming a shell of fine particles around a large particle core [65]. An aggregation model based on a solution of the Smoluchowski equation [66] to account for wet particle aggregation within the volcanic plume $[50,51]$ is included in the simulations here, with a chosen aggregate size of $\Phi=0$ and an aggregate density of $800 \mathrm{~kg} \mathrm{~m}^{-3}$ (see Section 4 for more details). Modeling schemes used in the simulations are summarized in Table 2.

Coupling WRF and FALL3D is common practice both in an operational and research context (e.g. [67-70]); however, ash advection and deposition calculations are usually carried out after the meteorological modeling has finished (i.e. offline coupling). Recent studies have revealed a high sensitivity of ash simulations to initialization data [71] and that online coupling (i.e. ash advection and deposition calculations at every meteorological model time step) is required to capture changes in the wind fields that affect ash dispersal and deposition [27,30], which can improve volcanic ash transport modeling [72]. In order to bridge the gap between the two methodologies, WRF output rate is set at $10 \mathrm{~min}$. For the resolution used, this output rate captures most of the resolved variabil- 


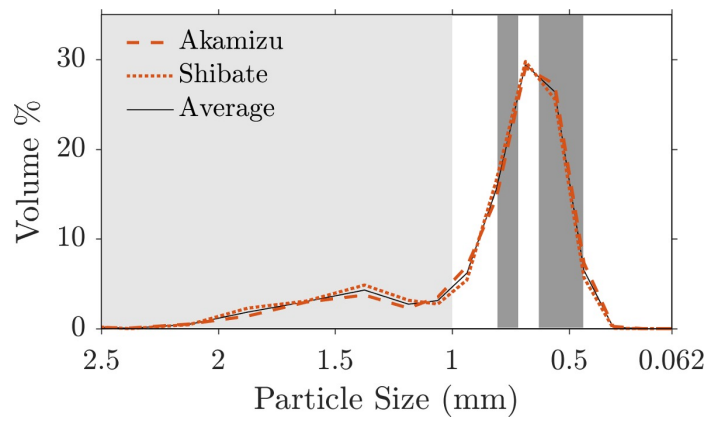

Fig. 4. Observed ash particle distribution (volume \%). Gray shaded areas indicate possible ash aggregate sizes. Note that the $x$-axis is reversed.

ity in the wind field and allows FALL3D simulations to be carried out in a quasi-online manner. Using the settings presented here WRF downscale simulations required $\sim 100$ min of computational time for $12 \mathrm{hr}$ of simulation using 144 processors at the Kyoto University supercomputer, while FALL3D simulations required $\sim 30$ min for 90 min of simulation using a single processor.

\section{Total Grain Size Distribution Determination}

Determining the Total Grain Size Distribution (TGSD) is an important challenge for the accurate simulation of volcanic ash dispersal and deposition (e.g. [73-75]), as the size (and density) of the particles controls terminal velocity which in turn affects the deposition patterns [76]. Usually the TGSD is determined by sampling a large amount of points along the dispersal axis of the volcanic cloud and, accounting for aggregation, reconstructing the original distribution at the plume. At Sakurajima, due to the continuous activity from the volcano collecting appropriate ground samples from specific eruptions can be challenging. The disdrometer network was employed to account for this; however, two key limitations are distance (currently disdrometers are only employed over the volcano) and the size cut-off at $0.2 \mathrm{~mm}$, meaning that smallfine ash particles are not registered. In order to bypass these limitations a novel modeling approach is used here.

The particle size distribution obtained by the disdrometer observations (with respect to the total particle volume and assuming spherical particles) can be seen in Fig. 4. The distribution at both disdrometer locations is almost identical and features a main maximum over moderatelysized particles $(0.5-0.7 \mathrm{~mm})$ and a secondary maximum over large particles (at $1.4 \mathrm{~mm}$ ). In a study over the volcano [65], ash aggregates were observed for sizes around the main maximum (marked with dark gray shading in Fig. 4), while aggregate sizes over $1 \mathrm{~mm}$ are commonly used in literature (e.g. [70]; light gray shading in Fig. 4). Aggregation leads to an increase in size and a decrease in density (compared to single particles), potentially impacting ash dispersal and deposition simulations, and is known to be an important process in Sakurajima $[64,65]$.

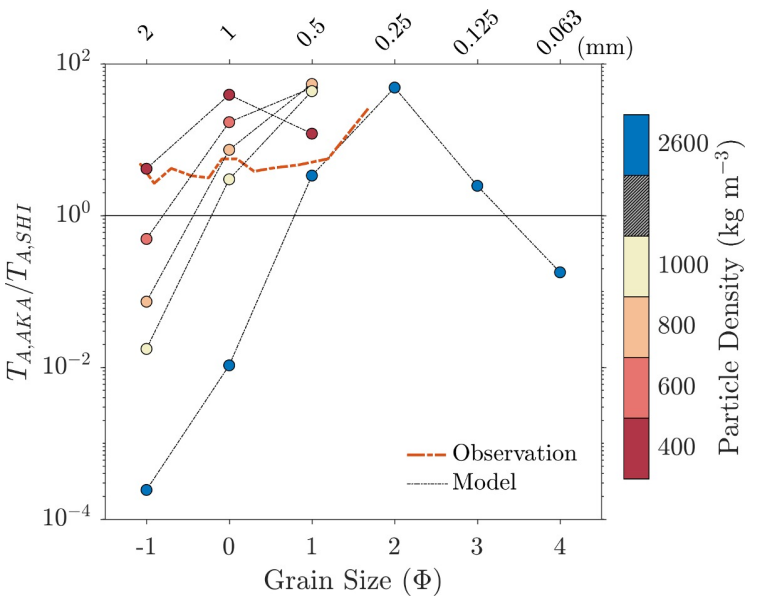

Fig. 5. Ash deposit thickness $\left(T_{A}\right)$ ratio between the Akamizu (AKA) and Shibate (SHI) disdrometer stations. The orange dot-dash line indicates observations, while the black lines indicate model results for varying ash particle density, indicated with different colors. Particle diameter is shown in $\Phi$ units with the corresponding size in $\mathrm{mm}$ showin in the top axis.

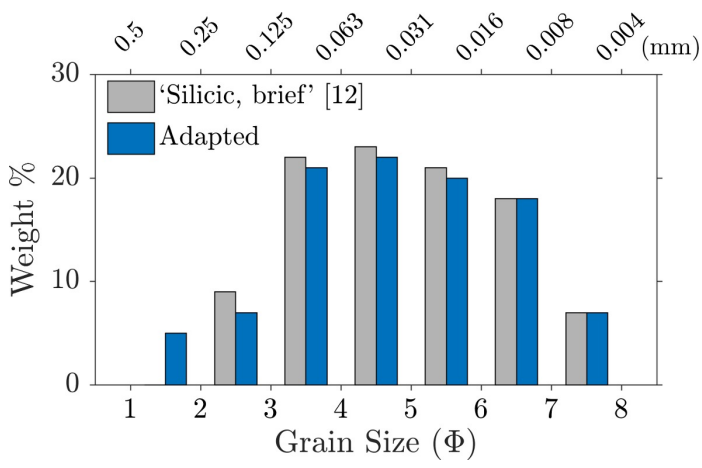

Fig. 6. Default total grain grain size distribution (TGSD) for a 'silicic, brief' type eruption [12] (gray boxes) and the adapted TGSD used in the FALL3D simulations here (blue).

In order to assess the possibility of aggregation in the disdrometer data, a series of exploratory simulations using the estimated total erupted mass $\left(3.2 \times 10^{8} \mathrm{~kg}\right)$ were carried out over the final forecast data (FC:0600JST; Fig. 3), as though all the ash was erupted as a single ash bin for each grain size $(\Phi)$ between -1:4 $\left(\Phi=-\log _{2}(d)\right.$, where $d$ is the particle diameter in $\mathrm{mm}$ ) and for different ash densities $\left(400,600,800,1000\right.$, and $\left.2600 \mathrm{~kg} \mathrm{~m}^{-3}\right)$.

The ratio of ash deposit thickness at the Akamizu and Shibate locations was plotted against the grain size ash bin tested (Fig. 5). The observed ratio (calculated using the disdromater observations and shown in orange) shows that at all observed particle sizes Akamizu received approximately 4 times as much ash as Shibate, increasing up to 35 times for small particle sizes $(\Phi>1)$. Results from the single ash particle density simulations $\left(2600 \mathrm{~kg} \mathrm{~m}^{-3}\right.$; blue markers) are a good match for particles in this size range ( $\Phi>1)$, but the $\Phi=1$ grain size represents a tran- 
sition point; for particle size larger than that, single particles in the model are deposited predominately over the Shibate location, with a Akamizu to Shibate ratio as low as $10^{-4}$ for $\Phi=-1$. Lowering the ash particle density (i.e. effectively testing for aggregates at the same size) reveals that an almost one to one model to observation agreement can be achieved for a particle density of $400 \mathrm{~kg} \mathrm{~m}^{-3}$ for $\Phi=-1$ (red marker at Fig. 5) and 800 for $\Phi=0$ (orange marker at Fig. 5). Overall, results indicate that large ash particles was most likely deposited as aggregates, while smaller ash as single particles. As $\Phi=1$ represents a transition point, it is likely that at this size, ash fell predominantly as single particles, mixed with an aggregate component as noted in [65].

Results suggest that the TGSD was mainly composed of medium to fine ash, with large aggregates produced after the eruption. This is in agreement with previous studies over the volcano [65]. In a previous ash dispersal study [27], a default 'silicic, brief' eruption TGSD [12] was used (see gray bars in Fig. 6). It was noted that although there was partial agreement with observations the distribution possibly missed an element of large ash particles. Disdrometer results here suggest that there were two missing key elements: (i) a percentage of larger $\Phi=1$ particles (see blue bars in Fig. 6), and (ii) a particle aggregation mechanism. For the sake of simplicity, the default TGSD [12] was modified to include $5 \%$ of $\Phi=1$ ash at single particle density (taken out of the distribution between $\Phi=2-5$ ) and an aggregate bin at $\Phi=0$ using the FALL3D aggregation model [50,51]. Note that the specific value for the $\Phi=1$ bin was used to get the best match against the disdrometer observations at Akamizu and Shibate (see Section 5). As such, the TGSD used is essentially tailored to the eruption studied. As the purpose of the study is to look at the sensitivities of the modeling method this empirical approach is used here; however, further study is needed to construct an appropriate default TGSD for the volcano.

\section{Control Simulation Results}

Initially a "control" simulation was carried out to test the model results using the optimal initialization data, i.e. the estimated total erupted mass and the WRF data based on the 0600JST MSM forecast data (i.e. the final forecast data released before the eruption). The eruption was initialized at the observed time (0719JST) and the duration for the eruption was set at $10 \mathrm{~min}$. The plume height was calculated by the FPLUME model at $4.4 \mathrm{~km}$ agl which was very close to the reported $4.7 \mathrm{~km}$ plume height (see Table 3). The simulation was run for a total of 90 mins after the eruption start.

In the simulation, dispersal occurs towards the southwest, similar to the JMA ash forecast (Fig. 7). The area of maximum ashfall is located over the southwestern shore of Sakurajima, while the overall ash deposition pattern has two secondary maxima, mirroring the deposition from the eruption studied in [27] which occurred under sim-
Table 3. FALL3D simulation details. Forecast simulations' names are based on the time of release of the meteorological forecast data used. The forecast data released at 0600JST (i.e. FC:0600JST) were the final forecast data released before the eruption. Total mass $\left(M_{T}\right)$ and mass discharge rate $(\dot{M})$ are based on observatory estimations [21] (see Fig. 9 for details), while plume height $\left(H_{P}\right)$ is estimated by the FPLUME model using the given discharge rate. The last row (shown in bold) shows the details for the control simulation.

\begin{tabular}{rccc}
\hline Name & $M_{T}\left(10^{8} \mathrm{~kg}\right)$ & $\dot{M}\left(10^{5} \mathrm{~kg} / \mathrm{s}\right)$ & $H_{P}(\mathrm{~km})$ \\
\hline FC:1800JST & 1 & 1.7 & 3.4 \\
FC:2100JST & 2.3 & 3.8 & 3.8 \\
FC:0000JST & 2.7 & 4.5 & 4.1 \\
FC:0300JST & 3.3 & 5.5 & 4.5 \\
FC:0600JST & 3.9 & 6.5 & 4.7 \\
E:0719JST & $\mathbf{3 . 2}$ & $\mathbf{5 . 4}$ & $\mathbf{4 . 4}$ \\
\hline
\end{tabular}

ilar atmospheric conditions. These secondary maxima are ubiquitous in ash deposition studies and have also been noticed using observational data around Sakurajima $[3,26]$. A number of mechanisms have been proposed to offer explanations, including particle aggregation [63], localized orographic effects [77] leading to force deposition of volcanic ash $[27,78,79]$, plume and atmosphere interaction [80], as well as due to the effect of different shear layers in the atmosphere [30].

Overall, the control simulation offers a notable improvement over the benchmark forecast (Fig. 7). Over the volcano ash deposition is only noted in the southwestern part, mirroring the disdrometer results. The area of ashfall over $1 \mathrm{~mm}$ closely matches the SVO post-eruption survey results. Ash deposit thickness over Akamizu and Shibate is very closely reproduced, with some timing differences due to the eruptive process not being resolved. However, this match is partially by design as the $\Phi=1$ ash bin percentage was chosen based on the ash deposit thickness. The simulation only overestimates ash at two points: the Hikinodaira peak (same as the JMA forecast data) and the JMA reported point over the southwestern shore of the volcano (which was given as an approximate value). Disagreement at the Hikinodaira disdrometer can be expected due to unresolved volcanogenic effects near the plume (e.g. $[3,80,81]$ ) and due to the model resolution; even at $\sim 300 \mathrm{~m}$, the distance between the vent and the disdrometer station is too short for advection to be properly resolved. Furthermore, disagreement can be expected because of the misrepresentation of the atmospheric state in the WRF model simulations. Even though WRF downscaled data show good agreement with the atmospheric sounding data (Fig. 2) with final Root Mean Square Error (RMSE) values for wind speed and direction $2.8 \mathrm{~m} \mathrm{~s}^{-1}$ and $23.1^{\circ}$ respectively, small deviations are inevitable, especially close to topographic maxima. Finally, although the observed pyroclastic flow had a relatively short length $(1.3 \mathrm{~km})$ the impact in the ash dispersal is not resolved and can thus be expected to lead to incon- 

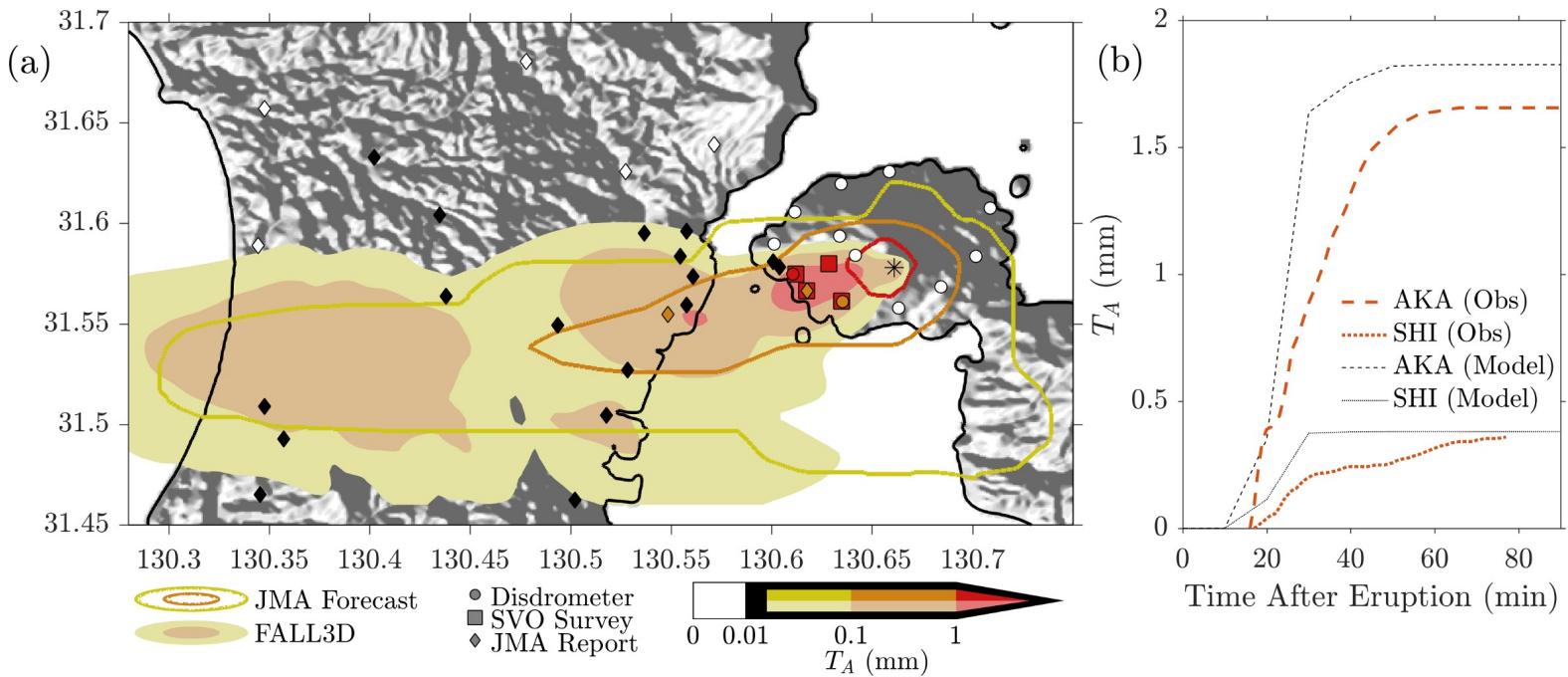

Fig. 7. (a) As Fig. 1b but with added results from the control FALL3D simulation (shown in lighter colors). A deposit thickness of $0.01 \mathrm{~mm}$ is assumed as the limit for the unspecified ('trace') contour. (b) Observed (orange) and modeled (black) accumulated ash deposit thickness at the two disdrometer stations.
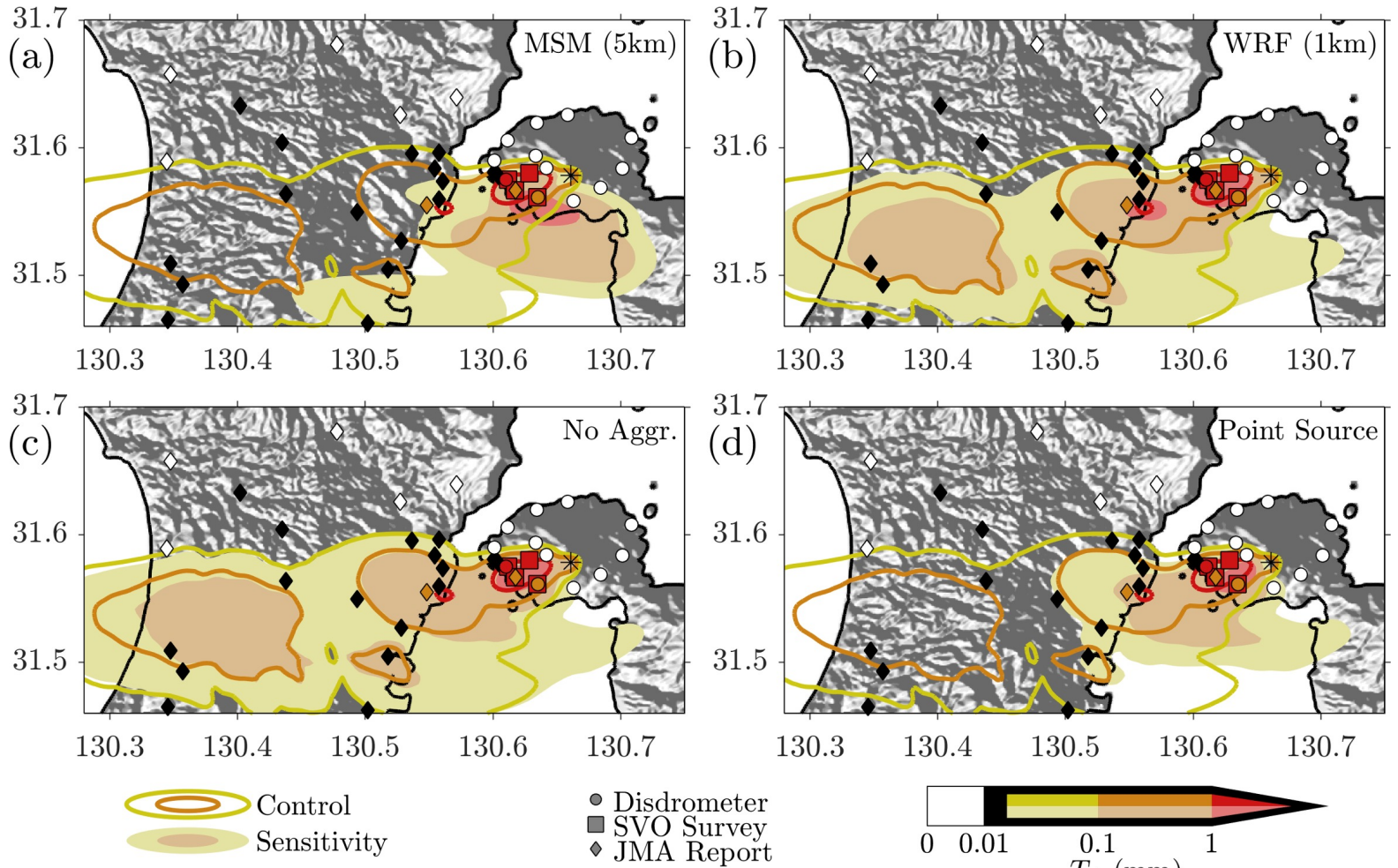

Fig. 8. Sensitivity tests using different model setups; specifically, as the control simulations (Table 2) but: (a) carried out over the original MSM data $(\Delta x=5 \mathrm{~km})$, (b) carried out over the coarse WRF domain data $(\Delta x=1 \mathrm{~km})$, (c) no aggregation scheme used, and (d) no plume model used (point source) and no aggregation. Results from the sensitivity simulations are shown shaded in light colors and results from the control simulation (i.e. Fig. 7) shown with line contours.

sistencies between the model and observations.

Four additional simulations were carried out using the 'control' settings with modifications in the model setup in order to test the sensitivity of the results (Fig. 8). In order to check the sensitivity to resolution, simulations were carried out using the original MSM data (Fig. 8a) and the WRF coarse $(\Delta x=1 \mathrm{~km})$ domain data (Fig. $8 \mathrm{~b})$. Results show a decrease in fidelity in both cases. Specifically, in the case of the MSM data, the dispersal pattern is markedly different with an overemphasized southerly component in the dispersal, and almost no ash dispersed to the west. In the case of the WRF coarse domain data, 
the effect is a more subtle southward shift in the dispersal. Switching the aggregation off also leads to a subtle changes in the pattern especially to the west of the volcano, leading to a small decrease in fidelity (Fig. 8c). Finally, using a point source (with $H_{P}=4.7 \mathrm{~km}$ ) instead of a plume model leads to a significant change in the resulting pattern, introducing a strong southwards component, leading to increased fanning and decreased ashfall over Kagoshima (Fig. 8d).

\section{Forecast Simulation Results}

A number of pseudo-forecast simulations were carried out to compare the difference in key diagnostics based on the combined effect of two factors: (i) the timing the forecast data are issued, (ii) the estimated eruptable mass. The assumed scenario is described in a schematic in Fig. 9. After allowing for the downscaling of the meteorological data, a number of forecast simulations are carried out concurrently for every hour of usable data. For these simulations the total mass value is chosen based on estimate at the time (shaded in the right-hand panel of Fig. 9 and shown in Table 3). Here in order to compare the results to the control simulation, the timing and duration of the eruption (0719JST and 10 min respectively) and FALL3D simulation period (0719-0849JST) were the same across all of the simulations in order to check key metrics' sensitivity to the two aforementioned factors. Using this scenario, the sensitivity of the forecast simulations to the combined effect of changes in the forecast as well as changes in the estimated mass are studied, in order to study the maximum amount of variability in the results.

Overall, ash dispersal patterns from the forecast simulations are surprisingly consistent (Fig. 10). Aside from the FC:1800JST simulation (initialized with forecast data released more than 13 hours before the eruption) simulation results are qualitatively similar, compared both against each other (Fig. 10b-e) as well as against the control simulation results. In all cases, the main point of maximum ashfall is located over the southwestern shore of Sakurajima with a secondary maximum over the eastern shore of Kagoshima west of the volcano. The dispersal axis and location of the other secondary maxima in ash deposition remains practically unchanged, with the variability seen caused both by the changes in the meteorological data as well as due to the fact that differences in the mass discharge rates used for each simulation lead to different plume heights (see Table 3), resulting to different vertical distributions of ash along the shear layers.

Quantitatively, the same conclusions can be seen by examining the evolution of the observations to model ratio of the ash deposit thickness over the Akamizu and Shibate stations (Fig. 10f). The nominal target accuracy for the simulations (a ratio between 0.5 and 2, i.e. a factor of 2 ) is indicated with dotted lines. Simulated ashfall over Akamizu shows a progressive increase in accuracy as the forecast time nears the eruption time, with an initial (and maximum) ratio of 64 (model underestimate) to a ratio

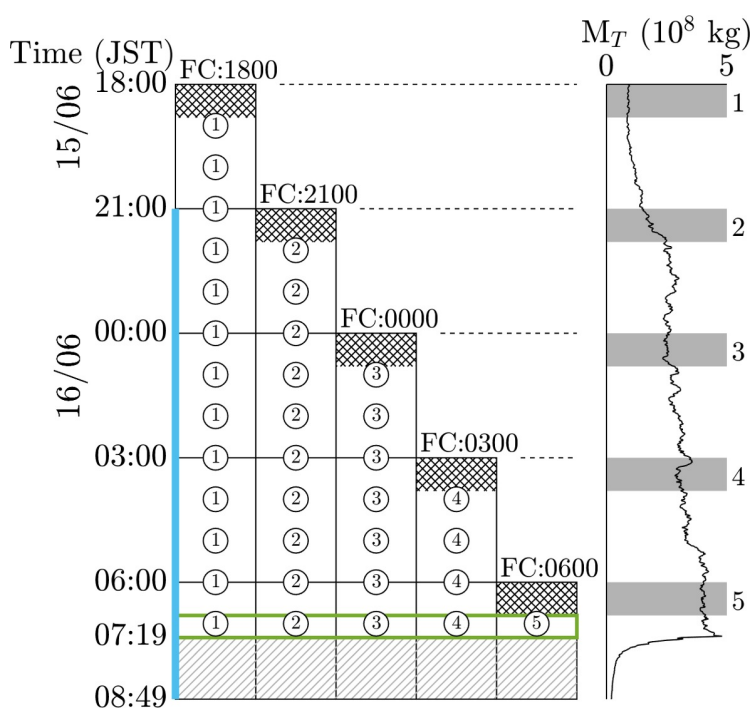

Fig. 9. Schematic representation of the forecast schedule explored. After the release of new forecast data (marked as 'FC:time') and after downscaling the data (marked with the cross-hatched pattern), a number of forecast simulations are carried out concurrently for every hour of forecast data (shown with the round markers with numbers). All forecasts use the average total mass estimate $\left(M_{T}\right)$ during the downscaling (gray shading in the right-hand panel with numbers indicating the corresponding simulations; values shown in Table 3). Simulations representative of the last forecast (green border) are analyzed (simulation period shown hatched in the left-hand side panel). For all the cases analyzed, meteorological simulations were carried out between 2100-0900JST (blue line).

about 1 in the FC:0600JST forecast simulation (Fig. 10f). The observation to model ratio for Shibate is consistently close to the target limits, starting at a ratio of 2.02 (model underestimate). Close to the eruption time forecast accuracy slightly degrades with a ratio of 0.35 (model overestimate) in the final forecast simulation. When taking results from both disdrometer stations into account, results from the pseudo-forecast simulations up to $4 \mathrm{hr}$ before the eruption are constrained between $0.25-4$ (factor of 4 ).

Results help clarify the temporal usability limits of the forecast approach. As seen both qualitatively and quantitatively, forecast simulations more than $\sim 10$ hours ahead of the eruption are associated with significant errors. However, fidelity improves for shorter forecast timescales - especially for results up to 2 forecast time steps before the eruption which have the potential to provide trustworthy ash forecasts. Considering that downscaling of the MSM forecast requires $\sim 1 \mathrm{hr}$, this means that the proposed system can follow the 3-hour MSM forecast cycle and provide accurate forecasts for a 6-hour period.

\section{Conclusions and Future Perspectives}

An experimental technique for high-resolution ash hazard forecasting was presented in detail and applied for an 

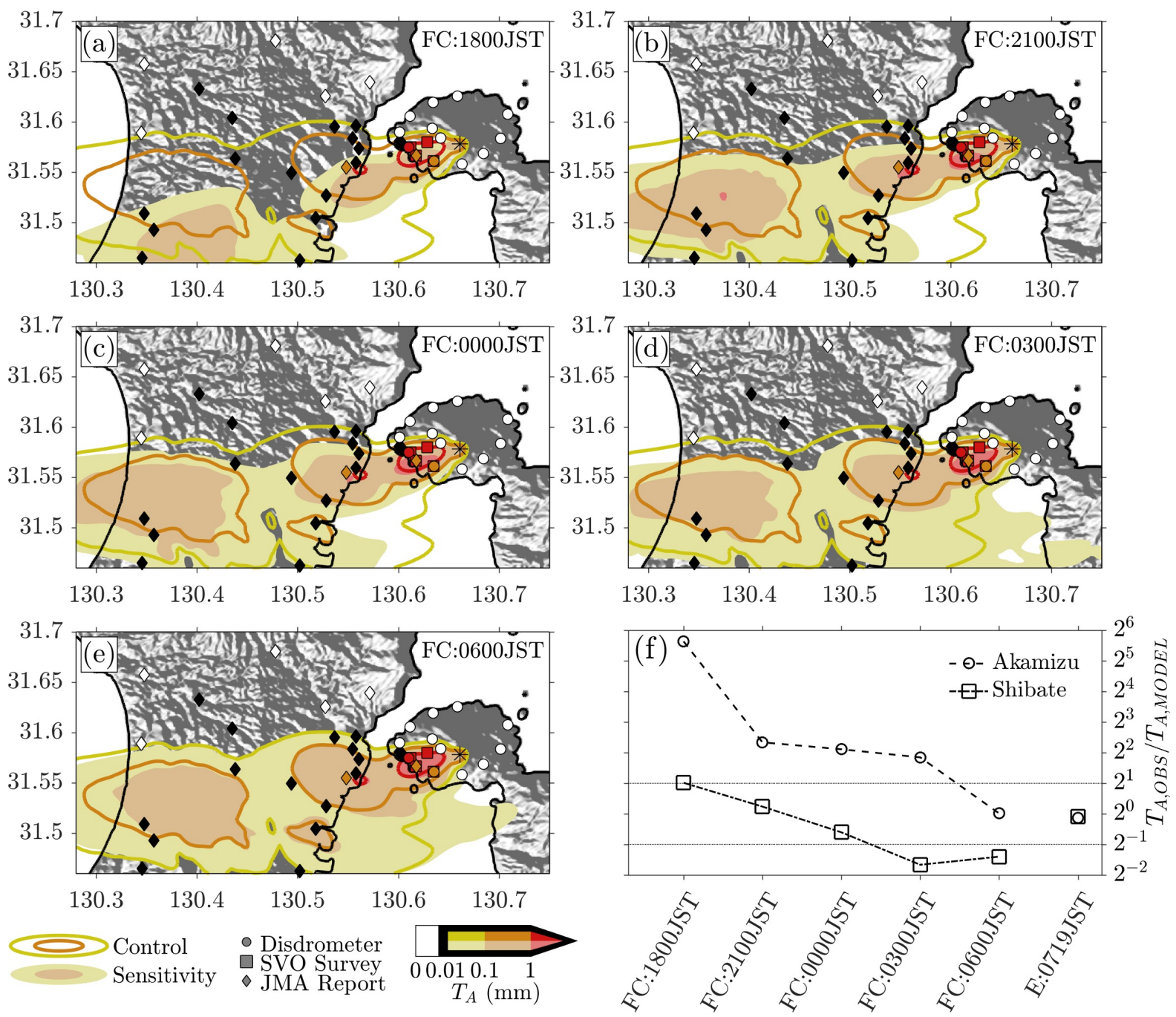

Fig. 10. As Fig. 8 but showing sensitivity tests based on downscaled MSM forecast data released at: (a) 15/06/2018:1800JST, (b) 15/06/2018:2100JST, (c) 16/06/2018:0000JST, (d) 16/06/2018:0300JST (e) 16/06/2018:0600JST. Results from the sensitivity simulations are shown shaded in light colors and results from the control simulation (i.e. Fig. 7a) shown with line contours. In all cases the eruption time is 0719JST and the FALL3D simulations are run between 0719-0849JST. See Table 3 for details. (f) Ash deposit thickness observation $\left(T_{A, O B S}\right)$ to model $\left(T_{A, M O D E L}\right)$ ratio for the two disdrometer locations against pseudo-forecast model run. The dotted lines indicate ratios of 0.5 and 2 .

eruption that occurred in Sakurajima on June 16, 2018. The WRF model was used for the dynamical downscaling of the JMA MSM forecast data, while the FALL3D model was used to model the release, transport and deposition of volcanic ash. ESPs were constrained using a combined observation and modeling approach: erupted mass was estimated using geophysical monitoring, while the TGSD was estimated via disdrometer ashfall data and exploratory computational modeling. With the refined ESPs a control simulation showed improvement over the JMA forecast and an excellent match against ashfall observations. Sensitivity tests using different model setup options also showed the significance of increased spatial and temporal resolution and the importance of the correct representation of the plume in the model.

Pseudo-forecast simulations designed to test model sensitivity to forecast release hour and eruptable mass es- timation up to $\sim 13$ hours before the eruptions, showed consistent results when using forecast data up to $\sim 10$ hours before the eruption, with results largely unchanged for forecast simulations up to $\sim 4$ hours before the eruption. These timescales are favorable for the computational time required for the combined modeling approach: using the current settings WRF downscale simulations require $100 \mathrm{~min}$ to produce results and can be confidently used for 6 hours, allowing for WRF downscale simulations to follow the 3 hour MSM forecast cycle. For the domain tested, FALL3D simulations required $30 \mathrm{~min}$ to produce results, which is similar to the JMA forecast time [13]. However, the FALL3D domain can be dynamically adjusted depending on the forecasted plume height in order to reduce computational time as necessary.

Initial results were seen to be encouraging but are based on a single eruption and the simulations were carried out 
Poulidis, A. P., Takemi, T., and Iguchi, M.

using tailored GSD data. In the future we aim to improve the proposed technique along the following lines:

- Refine the WRF and FALL3D model setup. Both models offer a number of physics and parameterization choices that need to be tested for different atmospheric and eruption settings.

- Refine domain and runtime settings in order to minimize processor use and computational time, including the dynamic selection of appropriate FALL3D boundaries.

- Study changes in the estimated TGSD based on a large number of eruptions and decide on a finalized default setting for forecasting.

- Study eruptions with different resulting volcanic plume heights $(1.5-5 \mathrm{~km})$ and check how the eruption strength impacts forecast sensitivity.

- Decide on an ESP parameter space in order to run scheduled ensemble simulations using FALL3D.

We hope that by gradually implementing changes from the above points we will be able to suggest a finalized method for operational forecasting that is accurate along the whole length of the ash cloud dispersal path.

\section{Acknowledgements}

This work was supported by the Integrated Program for the Next Generation Volcano Research and Human Resource Management project funded by the Japan Ministry of Education, Culture, Sports, Science and Technology (MEXT). Atmospheric sounding data were retrieved from the University of Wyoming archive. All data used in the study (seismograph and tilt meter data, postsurvey sampling data as well as the simulation results) are stored at Kyoto University and are available from the corresponding author. The authors would like to thank Takashi Unuma for sharing his expertise with the MSM forecast data. The authors would like to thank two anonymous reviewers for their helpful comments that have helped improve the manuscript.

\section{References:}

[1] C. Bonadonna, A. Folch, S. Loughlin, and H. Puempel, "Future developments in modelling and monitoring of volcanic ash clouds: Outcomes from the first IAVCEI-WMO workshop on Ash Dispersal Forecast and Civil Aviation," Bull. Volcanol., Vol.74, pp. 1-10, 2012.

[2] B. Langmann, A. Folch, M. Hensch and M. Volker, "Volcanic ash over Europe during the eruption of Eyjafjallajökull on Iceland, April-May 2010" Atmos. Environ., Vol.48, pp. 1-8, 2012.

[3] A. P. Poulidis, T. Takemi, A. Shimizu, M. Iguchi, and S. F. Jenkins, "Statistical analysis of dispersal and deposition patterns of volcanic emissions from Mt. Sakurajima, Japan," Atmos. Environ., Vol.179, pp. 305-320, 2018a.

[4] A. Hansell, and C. Oppenheimer, "Health hazards from volcanic gases: a systematic literature review," Arch. Environ. Health, Vol.59, pp. 628-639, 2004

[5] S. E. Hillman, C. J. Horwell, A. L. Densmore, D. E. Damby, B. Fubini, Y. Ishimine and M. Tomatis, "Sakurajima volcano: A physicochemical study of the health consequences of long-term exposure to volcanic ash,” Bull. Volcanol., Vol.74, pp. 913-930, 2012.

[6] S. F. Jenkins, T. M. Wilson, C. R. Magill, V. Miller, C. Steward, R. Blong, W. Marzocchi, M. Boulton, C. Bonadonna, and A. Costa, "Volcanic ash fall hazard and risk," in Global Volcanic Hazards and Risk, edited by S. C. Loughlin, R. S. J. Sparks, S. K. Brown, S. F. Jenkins, C. Vye-Brown, pp. 173-222, Cambridge Academic Press, Cambridge, 2015
[7] T. M. Wilson, C. Stewart, V. Sword-Daniels, G. S. Leonard, D. M. Johnston, J. W. Cole, J. Wardman, G. Wilson, and S. T. Barnard, "Volcanic ash impacts on critical infrastructure," Phys. Chem. Earth, Vol.45-46, pp. 5-23, 2012.

[8] J. L. Hayes, T. M. Wilson, and C. Magill, "Tephra fall clean-up in urban environments," J. Volcanol. Geotherm. Res., Vol.304, pp. $359-377,2015$

[9] A. Folch, "A review of tephra transport and dispersal models: evolution, current status, and future perspectives," J. Volcanol. Geophys. Res., Vol.235-236, pp. 96-115, 2012.

[10] R. S. J. Sparks, "Forecasting volcanic eruptions," Earth Planet. Sci. Lett., Vol.210, pp. 1-15, 2003.

[11] W. Degruyter, and C. Bonadonna, "Improving on mass flow rate estimates of volcanic eruptions," Geophys. Res. Lett., Vol.39, pp. L16308, 2012.

[12] L. G. Mastin, M. Guffanti, R. Servranckx, P. Webley, S. Barsotti, K. Dean, A. Durant, J. W. Ewert, A. Neri, W. I. Rose, D. Schneider, L. Siebert, B. Stunder, G. Swanson, A. Tupper, A. Volentik, and C. F. Waythomas, "A multidisciplinary effort to assign realistic source parameters to models of volcanic ash-cloud transport and dispersion during eruptions," J. Volcanol. Geotherm. Res., Vol.186, pp. 10-21, 2009.

[13] Y. Hasegawa, A. Sugai, Y. Hayashi, S. Hayashi, S. Saito and T Shimbori, "Improvements of volcanic ash fall forecasts issued by the Japan Meteorological Agency,” J. Applied Volcanol., Vol.4, pp. 1-12, 2015.

[14] M. Iguchi, "Volcanic activity of Sakurajima monitored using global navigation satellite system," J. Disaster. Res., Vol.13, pp. 518-525, 2018.

[15] M. Maki, M. Iguchi, T. Maesaka, T. Miwa, T. Tanada, T. Kozono, T. Momotani, A. Yamaji, and I. Kakimoto, "Preliminary Results of Weather Radar Observations of Sakurajima Volcanic Smoke," J. Disaster Res., Vol.11, pp. 15-30, 2016.

[16] S. Oishi, M. Iida, M. Muranishi, M. Ogawa, R. Hapsari, and M. Iguchi, "Mechanism of volcanic tephra falling detected by X-band multi-parameter radar," J. Disaster Res., Vol.11, pp. 43-52, 2016.

[17] A. Todde, R. Cioni, M. Pistolesi, N. Geshi, and C. Bonadonna, "The 1914 Taisho eruption of Sakurajima volcano: stratigraphy and dynamics of the largest explosive event in Japan during the twentieth century," Bull. Volcanol., Vol.79, pp. 72, 2017.

[18] M. Iguchi, H. Yakiwara, T. Tameguri, M. Hendrasto, and J Hirabayashi, "Mechanism of explosive eruption revealed by geophysical observations at the Sakurajima, Suwanosejima and Semeru volcanoes," J. Volcanol. Geotherm. Res., Vol.178, pp. 1-9, 2008.

[19] M. M. Morrissey, and L. G. Mastin, "Vulcanian eruptions," in Encyclopedia of Volcanoes, edited by H. Sigurdsson, pp. 463-476, Academic, San Diego, California, 2000

[20] M. Iguchi, T. Tameguri, Y. Ohta, S. Ueki, and S. Nakao, "Characteristics of Volcanic Activity at Sakurajima Volcano's Showa Crater During the Period 2006 to 2011," Bull. Volcanol. Soc. Japan, Vol.58, pp. 115-135, 2013

[21] M. Iguchi, "Method for real-time evaluation of discharge rate of volcanic ash - Case study on intermittent eruptions at the Sakurajima volcano, Japan -," J. Disaster Res., Vol.11, pp. 4-13, 2016.

[22] V. Freret-Lorgeril, F. Donnadieu, J. Eychenne, C. Soriaux, T. Latchimy, "In situ terminal settling velocity measurements at Stromboli volcano: Input from physical characterization of ash," J. Volcanol. Geotherm. Res., Vol.374, pp. 62-79, 2019.

[23] S. Biass, A. Todde, R. Cioni, M. Pistolesi, N. Geshi, and C. Bonadonna, "Potential impacts of tephra fallout from a large-scale explosive eruption at Sakurajima volcano, Japan," Bull. Volcanol. Vol.79, pp. 79, 2017

[24] C. Bonadonna, M. Pistolesi, W. Degruyter, M. Elissondo, and V. Baumann, "Dynamics of wind-affected volcanic plumes: The example of the 2011 Cordón Caulle eruption, Chile," J. Geophys. Res. Sol. Earth, Vol.120, pp. 2242-2261, 2015.

[25] M. Bursik, "Effect of wind on the rise height of volcanic plumes," Geophys. Res. Lett., Vol.28, pp. 3621-3624, 2001

[26] M. Oishi, K. Nishiki, N. Geshi, R. Furukawa, Y. Ishizuka, T. Oikawa, T. Yamamoto, G. Nanayama, A. Tanaka, A. Hirota, T. Miwa, and Y. Miyabuchi, "Distribution and mass of tephra-fall deposits from volcanic eruptions of Sakurajima Volcano based on posteruption surveys," Bull. Volcanol., Vol.80, pp. 42, 2018.

[27] A. P. Poulidis, T. Takemi, M. Iguchi, and I. A. Renfrew, "Orographic effects on the transport and deposition of volcanic ash: A case study of Mount Sakurajima, Japan," J. Geophys. Res. Atmos. Vol.122, pp. 9332-9350, 2017.

[28] Japan Meteorological Agency (JMA), "Report on Sakurajima Volcanic Activity, June 2018", https://www.data.jma.go.jp/svd/vois/data/tokyo/STOCK/monthly_vact_doc/fukuoka/18m06/506_18m06.pdf [accessed 20/11/2018]

[29] A. P. Poulidis, and T. Takemi, "A 1998-2013 climatology of Kyushu, Japan: seasonal variations of stability and rainfall," Int. J. Climatol., Vol.37, pp. 1843-1858, 2017. 
[30] A. P. Poulidis, J. C. Phillips, I. A. Renfrew, J. Barclay, A. Hogg, S F. Jenkins, R. Robertson and D. M. Pyle, "Meteorological controls on local and regional volcanic ash dispersal," Sci. Rep., Vol.8, pp. 6873, 2018b.

[31] JMA, "Sakurajima Ashfall Forecast (16/06/2018 - 07:46)", http://www.data.jma.go.jp/svd/vois/data/kouhai/jishin_data/.. data/contents/kazan/vol/ashfallq/20180615/Z_C_RJTD 20180615224609_EQV_CHT_JCIashfallq_JR506X_N1_image.pdf [accessed 20/11/2018]

[32] W. C. Skamarock, and J. B. Klemp, "A time-split nonhydrostatic atmospheric model for weather research and forecasting applications,’ J. Comput. Phys., Vol.227, pp. 3465-3485, 2008.

[33] W. C. Skamarock, J. B. Klemp, J. Dudhia, D. O. Gill, D. M. Barker, M. G. Duda, X.-Y. Huang, W. Wang, and J. G. Powers "A description of the advanced research WRF version 3," Tech. Rep. NCAR/TN-4751STR, 2008

[34] JMA, "JMA Numerical Weather Prediction", https://www.jma.go.jp/jma/jma-eng/jma-center/nwp/nwp-top.htm [accessed 20/11/2018]

[35] J. B. Klemp, J. Dudhia, and A. D. Hassiotis, "An upper gravitywave absorbing layer for NWP applications," Mon. Weather Rev., Vol.136, pp. 3987-4004, 2008.

[36] J. C. Knievel, G. H. Bryan, and J. P. Hacker, "Explicit numerical diffusion in the WRF model," Mon. Weather Rev., Vol.135, pp. 3808 3824, 2007.

[37] T. Takemi, and R. Rotunno, "The effects of subgrid model mixing and numerical filtering in simulations of mesoscale cloud systems," Mon. Weather Rev., Vol.131, pp. 2085-2101, 2003.

[38] J. C. Wyngaard, "Toward numerical modeling in the "terra incognita", J. Atmos. Sci., Vol.61, pp. 1816-1826, 2004.

[39] I. A. Boutle, A. Finnenkoetter, A. P. Lock, and H. Wells, "The London Model: forecasting fog at 333 m resolution," Q. J. Meteor. Soc., Vol.142, pp. 360-371, 2016.

[40] S.-Y. Hong, Y. Noh, and J. Dudhia, "A new vertical diffusion package with an explicit treatment of entrainment processes," Mon Weather Rev., Vol.134, pp. 2318-2341, 2006

[41] H. G. Morrison, G. Thompson, and V. Tatarskii, "Impact of cloud microphysics on the development of trailing stratiform precipitation in a simulated squall line: comparison of one- and two-moment schemes," Mon. Weather Rev., Vol.137, pp. 991-1007, 2009.

[42] M. J. Iacono, J. S. Delamere, E. J. Mlawer, M. W. Shephard, S. A Clough, and W. D. Collins, "Radiative forcing by longlived greenhouse gases: calculations with the AER radiative transfer models," J. Geophys. Res., Vol.113, pp. D13103, 2008

[43] A. C. M. Beljaars, "The parameterization of surface fluxes in largescale models under free convection," Q. J. Roy. Meteor. Soc., Vol.89, pp. 255-270, 1994

[44] A. J. Dyer, and B. B. Hicks, "Flux-gradient relationships in the constant flux layer,” Q. J. Roy. Meteor. Soc., Vol.96, pp. 715-721, 1970.

[45] C. A. Paulson, "The mathematical representation of wind speed and temperature profiles in the unstable atmospheric surface layer," J. Appl. Meteor., Vol.9, pp. 857-861, 1970

[46] E. K. Webb, "Profile relationships: The log-linear range, and extension to strong stability," Q. J. Roy. Meteor. Soc., Vol.96, pp. 67-90, 1970.

[47] D.-L. Zhang, and R. A. Anthes, "A high-resolution model of the planetary boundary layer- sensitivity tests and comparisons with SESAME-79 data," J. Appl. Meteor., Vol.21, pp. 1594-1609, 1982.

[48] J. Dudhia, "A multi-layer soil temperature model for MM5," Sixth PSU/NCAR Mesoscale Model Users' Workshop, 1996.

[49] A. Folch, A. Costa, and G. Macedonio, "FPLUME-1.0: An integral volcanic plume model accounting for ash aggregation," Geosci. Model Dev., Vol.9, pp. 431-450, 2016.

[50] A. Costa, A. Folch, and G. Macedonio, "A model for wet aggregation of ash particles in volcanic plumes and clouds: 1 . Theoretical formulation,” J. Geophys. Res., Vol.115, pp. B09201, 2010.

[51] A. Folch, A. Costa, A. Durant, and G. Macedonio, "A model for wet aggregation of ash particles in volcanic plumes and clouds: 2 . Model application,” J. Geophys. Res., Vol.115, pp. B09202, 2010.

[52] G. H. Ganser, "A rational approach to drag prediction of spherical and nonspherical particles," Powder Technol., Vol.77, pp. 143-152, 1993.

[53] E. Kaminski, S. Tait, and G. Carazzo, "Turbulent entrainment in jets with arbitrary buoyancy,” J. Fluid Mech., Vol.526, pp. 361-376, 2005

[54] P. M. Tate, "The rise and dilution of buoyant jets and their behaviour in an internal wave field," $\mathrm{PhD}$ Thesis, University of New South Wales, 2002.

[55] A. Costa, G. Macedonio, and A. Folch, "A three-dimensional Eularian model for transport and deposition of volcanic ashes," Earth Planet. Sci. Lett., Vol.241, pp. 634-647, 2006.
[56] A. Folch, A. Costa, and G. Macedonio, "FALL3D: A computational model for transport and deposition of volcanic ash," Comput. Geosci., Vol.35, pp. 1334-1342, 2009.

[57] G. Macedonio, A. Costa, and A. Folch, "Uncertainties in volcanic plume modeling: A parametric study using FPLUME,” J. Volcanol. Geotherm. Res., Vol.326, pp. 92-102, 2016.

[58] B. R. Morton, G. I. Taylor, and J. S. Turner, "Turbulent gravitationa convection from maintained and instantaneous source," P. R. Soc. London, Vol.234, pp. 1-23, 1956.

[59] G. Carazzo, E. Kaminski, and S. Tait, "On the rise of turbulent plumes: quantitative effects of variable entrainment for submarine hydromethermal vents, terrestrial and extra terrestrial explosive volcanism,” J. Geophys. Res., Vol.113, pp. B09201, 2008.

[60] P. M. Tate, and J. H. Middleton, "Unification of non-dimensional solutions to asymptotic equations for plumes of different shape," Bound.-Lay. Meteorol., Vol.94, pp. 225-251, 2000.

[61] G. G. J. Ernst, R. S. J. Sparks, S. N. Carey and M. I. Bursik, "Sedimentation from turbulent jets and plumes," J. Geophys. Res. Vol.101, pp. 5575-5589, 1996.

[62] A. W. Woods, "Moist convection and the injection of volcanic ash into the atmosphere," J. Geophys. Res., Vol.98, pp. 17627, 1993.

[63] R. J. Brown, C. Bonadonna, and A. J. Durant, "A review of volcanic ash aggregation," Phys. Chem. Earth, Vol.45-46, pp. 65-78, 2012.

[64] J. S. Gilbert, and S. J. Lane, "The origin of accretionary lapilli," Bull. Volcanol., Vol.56, pp. 398-411, 1994.

[65] G. Bagheri, E. Rossi, S. Biass, and C. Bonadonna, "Timing and nature of volcanic particle clusters based on field and numerical investigations," J. Volcanol. Geophys. Res., Vol.327, pp. 520-530, 2016.

[66] M. Smoluchowski, "Veruch einer mathematischen Theorie der Koagulationkinetic kolloider Lösungen,” Z. Phys. Chem., Vol.92, pp. 128-168, 1917.

[67] S. Corradini, L. Merucci, and A. Folch, "Volcanic ash cloud properties: comparison between MODIS satellite retrievals and FALL3D transport model," IEEE Geosci. Remote S., Vol.8, pp. 248-252, 2011.

[68] A. Folch, O. Jorba, and J. Viramonte, "Volcanic ash forecast - application to the May 2008 Chaitén eruption," Nat. Hazards Earth Syst. Sci., Vol.8, pp. 927-940, 2008

[69] M. S. Osores, A. Folch, E. Collini, G. Villarosa, A. Durant, G. Pujol, and J. G. Viramonte, "Validation of the FALL3D model for the 2008 Chaitén eruption using field and satellite data," Andean Geol., Vol.40, pp. 262-276, 2013.

[70] M. Poret, A. Costa, A. Folch, and A. Martì, "Modelling tephra dispersal and ash aggregation: The 26th April 1979 eruption, La Soufrière St. Vincent," J. Volcanol. Geotherm. Res., Vol.347, pp. 207-220, 2017.

[71] G. C. Mulena, D. G. Allende, S. E. Puliafito, S. G. Lakkis, P. G. Cremades, and A. G. Ulke, "Examining the influence of meteorological simulations forced by different initial and boundary conditions in volcanic ash dispersion modelling," Atmos. Res., Vol.176-177, pp. 29-42, 2016.

[72] A. Martì, and A. Folch, "Volcanic ash modeling with the NMMB MONARCH-ASH model: quantification of offline modeling errors," Atmos. Chem. Phys., Vol.18, pp. 4019-4038, 2018.

[73] C. Bonadonna, and B. F. Houghton, "Total grain-size distribution and volume of tephra-fall deposits," Bull. Volcanol., Vol.67, pp $441-456,2005$.

[74] F. Girault, G. Carazzo, S. Tait, F. Ferrucci, and E. Kaminski, "The effect of total grain-size distribution on the dynamics of turbulen volcanic plumes," Earth Planet. Sci. Lett., Vol.394, pp. 124-134, 2014.

[75] E. Rossi, C. Bonadonna, and W. Degruyter, "A new strategy for the estimation of plume height from clast dispersal in various atmospheric and eruptive conditions," Earth Planet. Sci. Lett., Vol.505, pp. 1-12, 2019.

[76] C. Bonadonna, G. G. J. Ernst, and R. S. J. Sparks, "Thickness variations and volume estimates of tephra fall deposits: the importance of particle Reynolds number," J. Volcanol. Geotherm. Res., Vol.81, pp. 173-187, 1998

[77] R. B. Smith, "Linear theory of stratified hydrostatic flow past an isolated mountain," Tellus, Vol.32, pp. 348-364, 1980

[78] S. F. L. Watt, J. S. Gilbert, A. Folch, J. C. Phillips, and X. M. Cai, "An example of enhanced tephra deposition driven by topographically induced atmospheric turbulence," Bull. Volcanol., Vol.77, pp. 35,2015 .

[79] J. Eychenne, A. C. Rust, K. V. Cashman, and W. Wobrock, "Distal Enhanced Sedimentation From Volcanic Plumes: Insights From the Secondary Mass Maxima in the 1992 Mount Spurr Fallout Deposits,” J. Geophys. Res., Vol.122, pp. 7679-7697, 2017.

[80] I. Manzella, C. Bonadonna, J. C. Phillips, and H. Monnard, "The role of gravitational instabilities in deposition of volcanic ash," Geology, Vol.43, pp. 211-214, 2015. 
Poulidis, A. P., Takemi, T., and Iguchi, M.

[81] A. P. Poulidis, I. A. Renfrew, and A. J. Matthews, "Thermally induced convective circulation and precipitation over an isolated volcano," J. Atmos. Sci., Vol.73, pp. 1667-1686, 2016

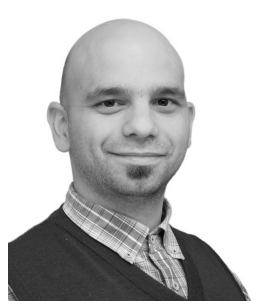

\section{Name:}

Alexandros Panagiotis Poulidis

\section{Affiliation:}

Research Assistant Professor, Disaster Prevention Research Institute (DPRI), Kyoto University

\section{Address:}

Gokasho, Uji, Kyoto 611-0011

Brief Career:

2015- PhD, University of East Anglia, UK

2016- JSPS International Fellow, DPRI

2018- Research Assistant Professor, DPRI

Selected Publications:

- A. P. Poulidis, T. Takemi, A. Shimizu, M. Iguchi, and S. F. Jenkins,

"Statistical analysis of dispersal and deposition patterns of volcanic emissions from Mt. Sakurajima, Japan," Atmos. Environ., Vol.179, pp. 305-320, 2018

- A. P. Poulidis, I. A. Renfrew, and A. J. Matthews, "Thermally induced convective circulation and precipitation over an isolated volcano," J.

Atmos. Sci., Vol.73, pp. 1667-1686, 2016

Academic Societies \& Scientific Organizations:

- Japan Geoscience Union (JpGU)

- International Association of Volcanology and Chemistry of the Earth's

Interior (IAVCEI)

- Royal Meteorological Society (RMetS)

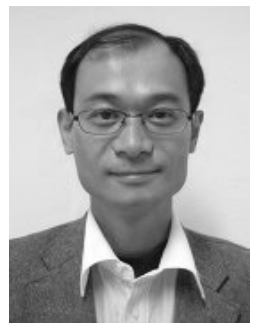

Name:

Tetsuya Takemi

\section{Affiliation:}

Associate Professor, Disaster Prevention Research Institute, Kyoto University

\section{Address:}

Gokasho, Uji, Kyoto 611-0011

Brief Career:

1999- Research Associate, Osaka University, Japan 2004- Lecturer, Tokyo Institute of Technology, Japan

2007- Associate Professor, DPRI

\section{Selected Publications:}

- N. Mori., and T. Takemi "Impact assessment of coastal hazards due to future changes of tropical cyclones in the North Pacific Ocean," Weather Clim. Extremes, Vol.11, pp. 53-69, 2016

- T. Takemi, and R. Rotunno, "The effects of subgrid model mixing and numerical filtering in simulations of mesoscale cloud systems," Mon.

Weather Rev., Vol.131, pp. 2085-2101, 2003

Academic Societies \& Scientific Organizations:

- Japan Geoscience Union (JpGU)

- Meteorological Society of Japan (MSJ)

- American Geophysical Union (AGU)

- American Meteorological Society (AMS)

- Asia Oceania Geosciences Society (AOGS)

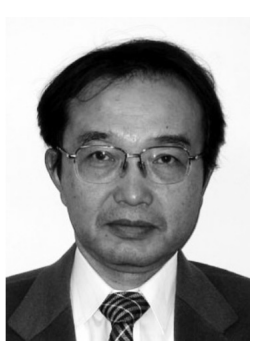

Name:

Masato Iguchi

\section{Affiliation:}

Professor, Disaster Prevention Research Institute, Kyoto University

Address:

1722-19 Sakurajima-Yokoyama, Kagoshima 891-1419, Japan

Brief Career:

1981- Research Associate, DPRI

1995- Associate Professor, DPRI

2012- Professor, DPRI

\section{Selected Publications:}

- M. Iguchi, "Magma movement from deep to shallow Sakurajima volcano as revealed by geophysical observations," Bull. Volcanol. Soc. Japan, Vol.58, pp. 1-18, 2013

- T. Nishimura, and M. Iguchi, "Volcanic Earthquakes and Tremors in Japan," Kyoto University Press, p. 253, 2011

Academic Societies \& Scientific Organizations:

- Volcanological Society of Japan (VSJ)

- American Geophysical Union (AGU)

- International Association of Volcanology and Chemistry of the Earth's Interior (IAVCEI) 